\title{
Online peer mentorship programmes for children and adolescents with neurodevelopmental disabilities: A systematic review
}

\author{
Shikha Saxena ${ }^{1,2}$ @ | Jacob Mitchell ${ }^{3}$ | Annahita Ehsan ${ }^{4}$ | Annette Majnemer ${ }^{5}$ | \\ Keiko Shikako-Thomas ${ }^{5}$
}

${ }^{1}$ Children's Hospital of Eastern Ontario Research Institute, Ottawa, Ontario, Canada

${ }^{2}$ University of Ottawa, Ottawa, Ontario,

Canada

${ }^{3}$ Poznań University of Medical Sciences, Poznań, Poland

${ }^{4}$ University of Lausanne, Lausanne, Switzerland

${ }^{5}$ School of Physical \& Occupational Therapy, McGill University, Quebec, Canada

\section{Correspondence}

Shikha Saxena, Children's Hospital of Eastern Ontario Research Institute, 401 Smyth Rd, Ottawa, ON K1H 5B2, Canada, and University of Ottawa, 75 Laurier Ave E, Ottawa, ON K1N 6N5. Canada.

Email: shikha.saxena@mail.mcgill.ca

\begin{abstract}
Background: Children and adolescents with neurodevelopmental disabilities may be less well integrated into their community than their peers. Online groups can be particularly accessible for individuals with neurodevelopmental disabilities, as individuals may be able to connect with a larger network than they would in their local community. This systematic review aimed at estimating the effectiveness of online peer mentorship programmes on children and adolescent's participation in life situations.

Methods: A systematic review was conducted to search Medline, PsycINFO, Embase, CINAHL, and Education Research Complete (ERIC) electronic databases. Thematic analysis was done for studies that used qualitative methodology.

Results: Eleven articles were included, and they examined the influences of five different structured online peer mentorship intervention programmes and six different online support groups. The disabilities included cerebral palsy $(n=3)$, autism spectrum disorder $(n=3)$, spina bifida $(n=2)$, attention deficit hyperactivity disorder $(n=2)$, and other neurodevelopmental disorders. The mentors included in the studies were caregivers of children with disabilities, youth and adults with disabilities, and a virtual peer actor. The mentees included in the studies were youth with disabilities (age 10-19 years) and their families. Intervention characteristics varied across the studies but consistently showed a unique potential to facilitate social networking and support. Intervention programmes with specific content and structure showed better participation outcomes than unstructured interventions. Presence of a moderator and participant characteristics (age and sociocultural background) was suggested to influence the outcomes of interventions.

Conclusions: Online peer mentorship programmes appear to have positive influence on social engagement and participation in life situation for children and adolescents with disabilities. This paper discusses several areas that should be considered in future research studies to improve potential effectiveness and use of study designs that help to establish not only if interventions work but also for whom they work best and why.
\end{abstract}




\section{KEYWORDS}

family, friend, group, internet, mobile, support

\section{1 | INTRODUCTION}

Participation in meaningful and age-appropriate life situations and roles is important for children and youth, to include children and youth with disabilities. The International Classification of Functioning, Disability and Health classifies participation in life situations in a number of domains to include communication, learning and applying knowledge, interpersonal interactions and relationships, and participation in other domestic, community, social, and civic life areas (Organization, 2002). Participation in life situations is often divided into three settings when it comes to children and adolescents (youth): home, school, and community. For youth, these activities can include play, leisure, socializing using technology, school preparation, homework, getting together with peers inside and outside of school, structured and unstructured physical activities, community gatherings, and religious events (Coster et al., 2012). Youth with neurodevelopmental disabilities (Dahan-Oliel, Shikako-Thomas, \& Majnemer, 2012) can have difficulties participating in different activities and situations on a day-to-day basis, and these frequent barriers to participation include a limited number of peers with disabilities integrated into community programmes, limited resources to adapt the environment, and low social support. For parents, a frequent barrier to participation is a lack of information on existing programmes and strategies to help their children participate in these activities (Anaby et al., 2014; ShikakoThomas et al., 2013).

Youth and parents may choose to try to overcome these difficulties by seeking information and support from various sources, such as local communities, organizations, and online groups. Online groups in particular can play an important role in helping individuals cope with health-related issues. These groups can simultaneously provide individuals with practical information and socialemotional support (Coulson, Buchanan, \& Aubeeluck, 2007). Online contexts provide unique, accessible opportunities for peer mentorship. For the purpose of this manuscript, we will adopt the definition of peer mentorship as a situation where a person who has lived through a specific experience (peer mentor) and a person (or a small group) who is new to that experience (peer mentee) connect in a structured setting or context (Bozeman \& Feeney, 2007). Peer mentorship provides individuals living with a particular life experience with the opportunity to learn from those who have adapted to (or rehabilitated from) similar life experiences. Mentors can provide opportunities for, or facilitate access to, resources such as education, recreation, and support to the mentee. In this case, the life experience can be living with a disability (youth) or having a child with a disability (parents).

Online peer mentorship programmes have the potential to improve the lives of youth with disabilities and their families by

\section{KEY MESSAGES}

- Youth with neurodevelopmental disabilities and their families require peer support to share and cope up with life experiences.

- Structured online peer mentorship programmes would help improve the social engagement and participation in life situations of youth with neurodevelopmental disabilities and their families.

- Further research is needed to develop evidence-based online peer intervention programmes that would help individuals with disabilities and their families cope up with specific needs.

increasing accessibility to peer mentorship and having potentially low costs. Advantages of online peer mentorship groups include 24-hr access, high availability of information and social support, and the opportunity to speak to individuals who can personally relate to certain experiences, regardless of geographical boundaries (Lasker, Sogolow, \& Sharim, 2005). Online peer mentorship programmes could be complementary to rehabilitation programmes, given their accessibility and the potential to match individuals. Despite the potential benefits of online peer mentorship for rehabilitation services, little is known about the structure and outcomes of online peer mentorship programmes. Empirical evidence is needed to understand whether online peer mentorship programmes have the potential to support rehabilitation outcomes, such as participation in everyday activities. This systematic review aims to systematically synthesize the current evidence on online peer mentorship programmes for youth with neurodevelopmental disabilities and their parents. The objectives of this review are to (a) identify the effectiveness of online peer mentorship programmes on children and adolescent's participation in life situations and (b) make recommendations on whether online peer mentorship programmes should be complementary to rehabilitation programmes.

\section{2 | METHODS}

The aim of this systematic review was to synthesize the evidence identifying the effectiveness of online peer mentorship programmes on the participation in life situations for children and adolescents with neurodevelopmental disabilities. The present systematic review was 
performed based on the Preferred Reporting Item for Systematic Review and Meta-analysis statement (Appendix A). A protocol was registered on Prospero database (CRD42019126505).

\subsection{Keywords and search terms}

Medline, PsycINFO, Embase, CINAHL, and Education Research Complete (ERIC) electronic databases were searched for studies that were published up until July 15,2019 . The search strategy was constructed with the help of a health sciences librarian and contained four blocks of keywords related to types of online platform (e.g., the Internet and the web), types of social support (e.g., peer mentorship and support system) age groups of youth (e.g., child and adolescent), participant roles (e.g., mentor and parent), and type of disability (e.g., neurologic and cerebral palsy). The search criteria and a detailed example of the Medline search strategy are available in Appendix B.

\subsection{Inclusion and exclusion criteria}

Studies were considered eligible if they (a) presented online peer mentorship programmes involving children with disabilities and/or their family members and (b) aimed to promote the participation of children with disabilities in life situations, such as self-care, communication play, leisure, and recreation. Studies were excluded if interventions were provided exclusively by health or education professionals as this did not fall under our definition of peer. The review was limited to neurodevelopmental disabilities in order to increase the comparability and homogeneity of the studies included. The full eligibility criteria are listed in Table 1.

\section{3 | Data screening}

Two authors (S. S. and J. M.) searched the databases. The authors independently conducted the first search based on titles and abstracts in Psyclnfo and ensured agreement by comparing and discussing what they retrieved. They screened $10 \%$ articles together and discussed any disagreements on study selection based on abstracts. After consensus was reached on the clarity of criteria, the authors divided the remaining databases and finished the search. All of the studies were initially screened by abstracts and saved for further assessment in the full-text stage if they met selection criteria. The references of all of the selected articles were scanned for other studies that might meet the inclusion criteria and were not identified in the databases search.

\subsection{Data extraction}

Information extracted included outcomes from both quantitative and qualitative studies. For the quantitative articles, we extracted at coefficients and interpretations presented within each study. For the qualitative studies, we extracted quotes presented within the study, as well as second-order qualitative interpretations (researcher interpretation, statements, assumptions, and ideas). We also extracted bibliographic and methodological information about each study: name of the author, year of publication and country on publication, information on the online platform used for the peer mentorship, target disability group, sample size, intervention components, measurement tools, and outcomes arising from the mentorship. A data extraction table was developed for this review (Table 2). Two authors extracted the data (S. S. and J. M.), and a third author (K. S. T.) helped resolve any disagreements during regular meetings. The two authors had an

TAB LE 1 Selection criteria for studies

\begin{tabular}{|c|c|c|}
\hline Study Characteristics & Inclusion criteria & Exclusion criteria \\
\hline Study design & Quantitative and qualitative published studies & Unpublished studies and grey literature \\
\hline $\begin{array}{r}\text { Programmes- } \\
\text { intervention }\end{array}$ & $\begin{array}{l}\text { Interactive online-based peer mentorship programmes- } \\
\text { including personal email exchanges }\end{array}$ & $\begin{array}{l}\text { Peer mentorship that is not online and mentorship that is } \\
\text { not targeted to the individual (e.g., blogs, general forum } \\
\text { posts, and personal story telling). }\end{array}$ \\
\hline $\begin{array}{l}\text { Definition of peer } \\
\text { mentorship }\end{array}$ & $\begin{array}{l}\text { Peer to peer (child with a disability, youth with a disability, or } \\
\text { parent of child with disability) and person (child with } \\
\text { disability, youth with disability, or parent with disability) to } \\
\text { community worker (e.g., parent without a child with } \\
\text { disability and peer support workers) }\end{array}$ & $\begin{array}{l}\text { Mentorship that is not peer based, that is, mentorship from } \\
\text { someone from a clinical background (e.g., social worker, } \\
\text { psychologist, psychiatrist, occupational therapist, } \\
\text { physiotherapist, doctor, and nurse healthcare } \\
\text { professional). }\end{array}$ \\
\hline Definition of disability & $\begin{array}{l}\text { Any neurodevelopmental childhood disability (developmental } \\
\text { disabilities that have a neurologic origin) }\end{array}$ & $\begin{array}{l}\text { Not including mental health disorders such as eating } \\
\text { disorders, depression in children or youth, psychosis in } \\
\text { children or youth, children or youth with alcohol or } \\
\text { substance use disorders, or suicide or infant death. }\end{array}$ \\
\hline Population & $\begin{array}{l}\text { Children and youth (ages } 0-18 \text { ) with neurodevelopmental } \\
\text { disabilities and parents of children and youth with } \\
\text { neurodevelopmental disabilities }\end{array}$ & $\begin{array}{l}\text { Children and youth without disability; children and youth } \\
\text { with a mental health condition; and parents of children } \\
\text { without a disability and with mental health conditions }\end{array}$ \\
\hline Location & Any country & \\
\hline Language & English or French & Languages outside of English or French \\
\hline Date & Any article up to July 15, 2019 & \\
\hline
\end{tabular}


善衰言

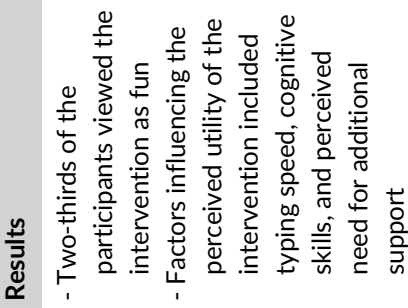

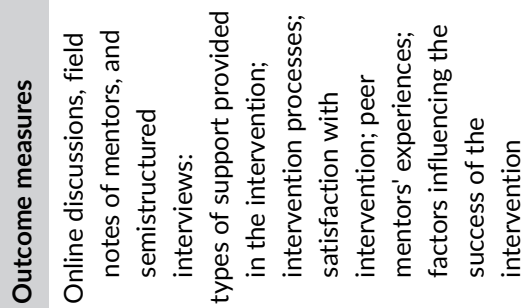

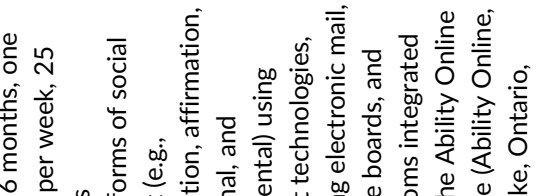

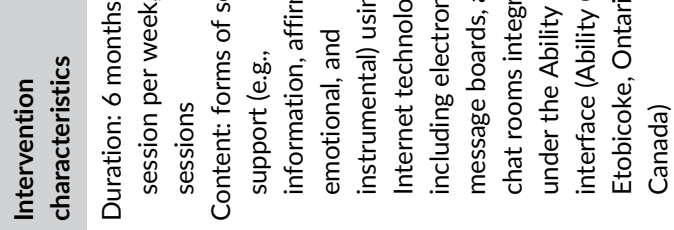

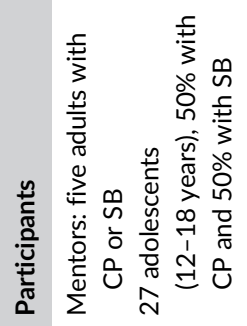

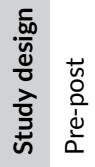

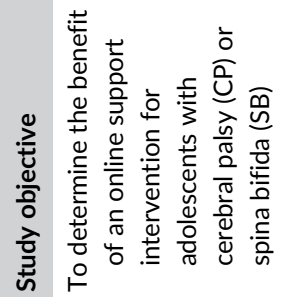

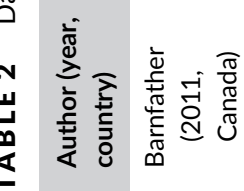

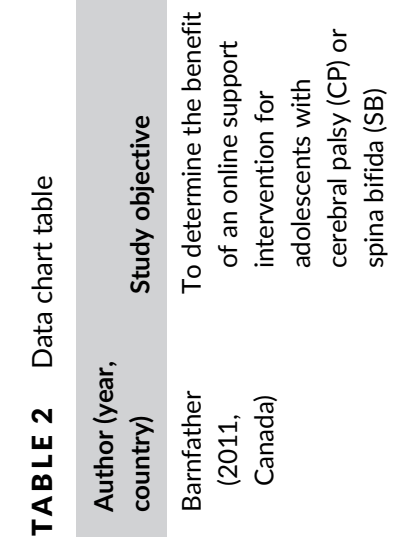

ᄒ

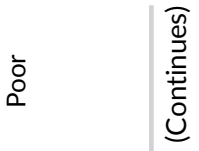

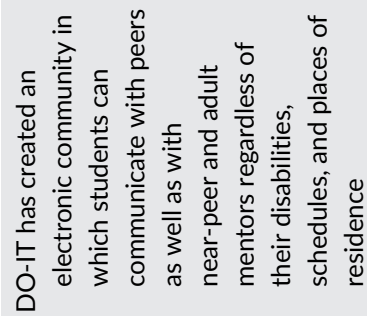

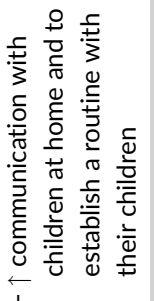

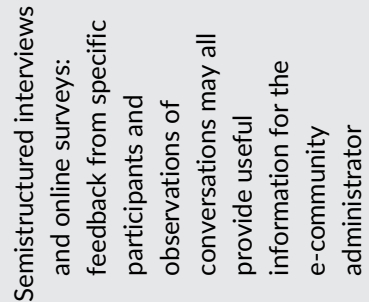

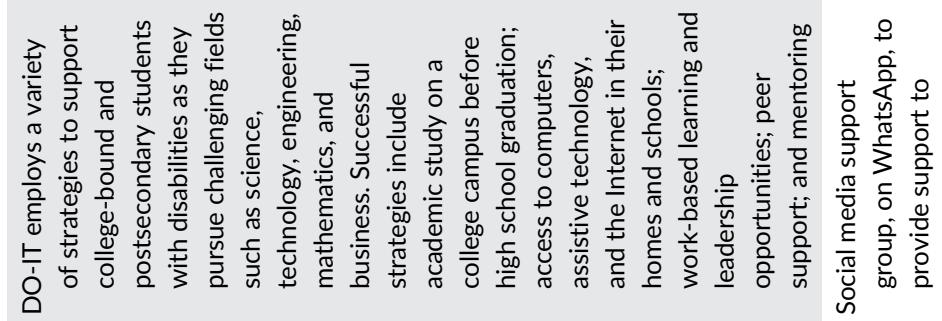
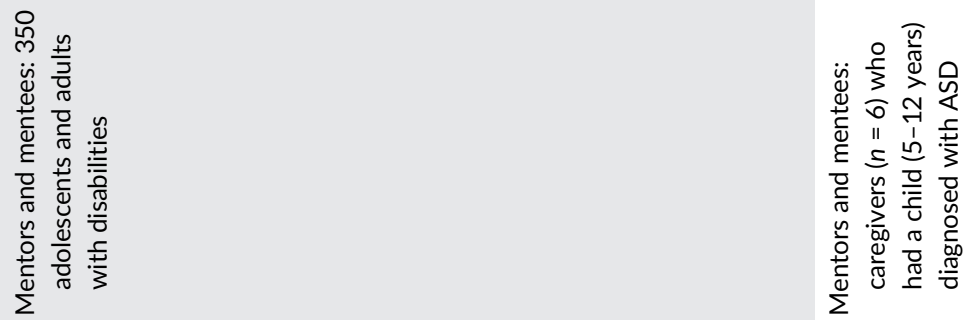

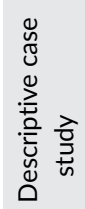
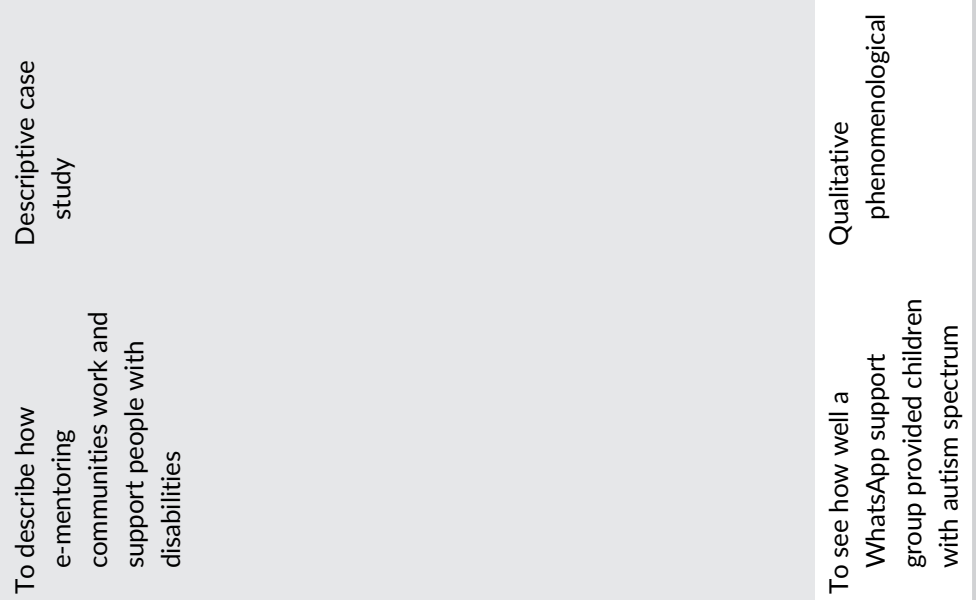

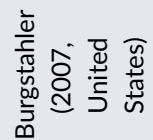

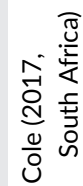




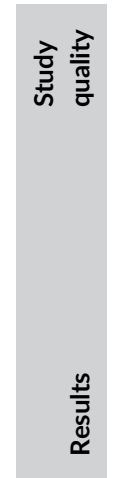

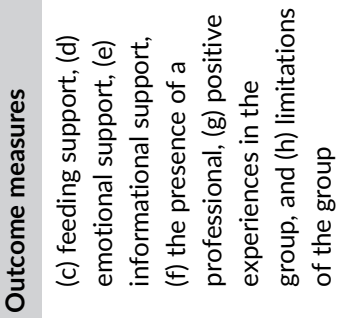

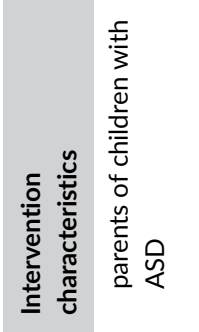

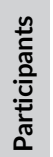

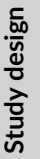

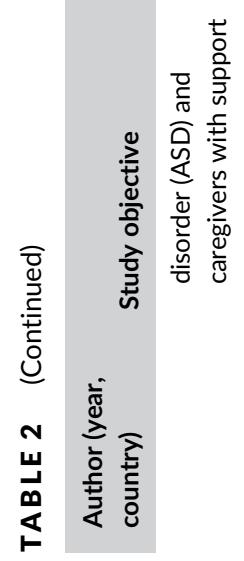

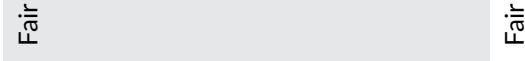
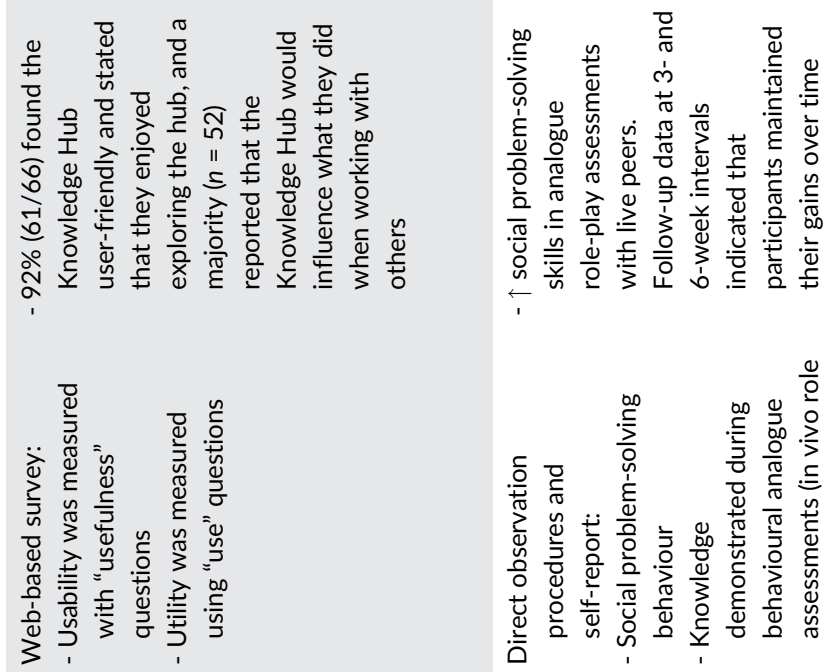

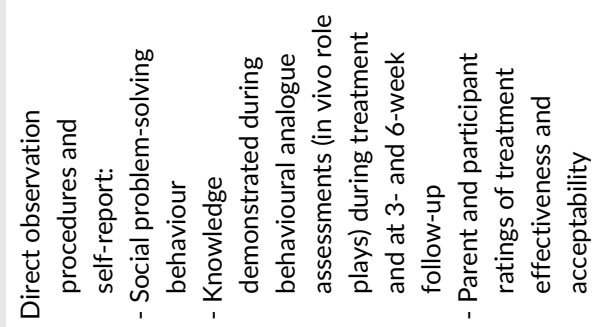

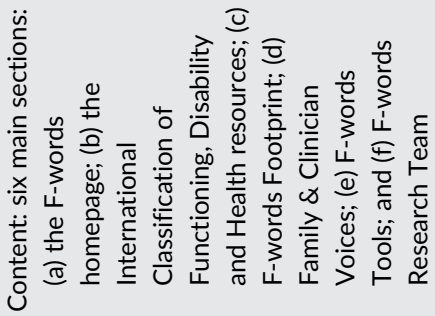

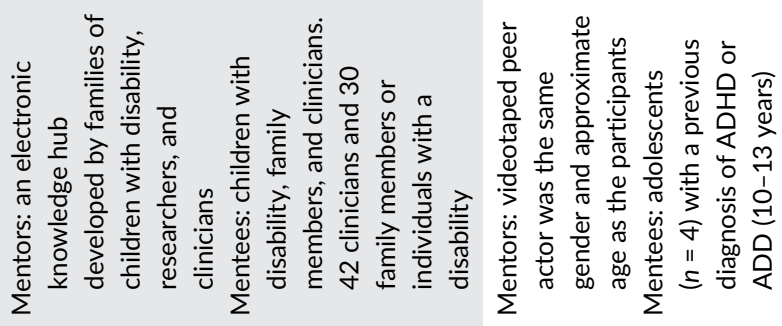

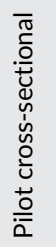

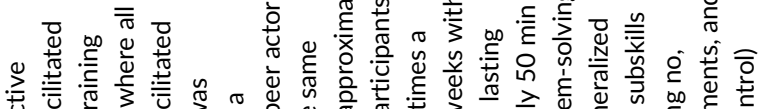

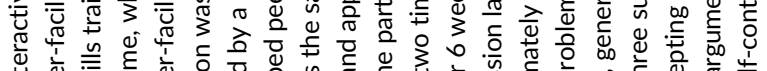

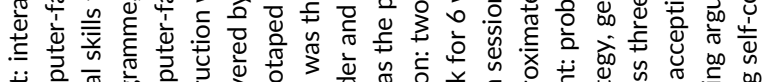

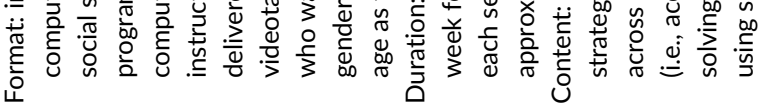

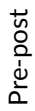
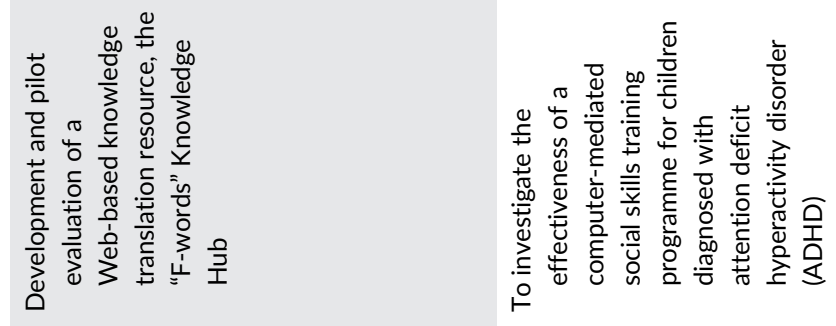

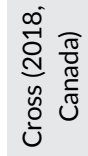

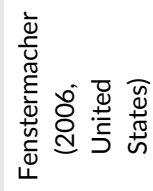




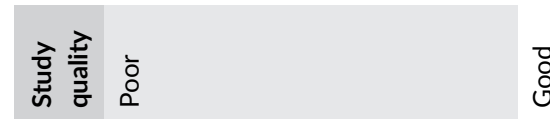

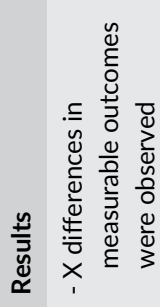

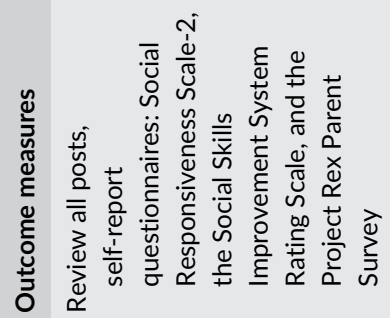

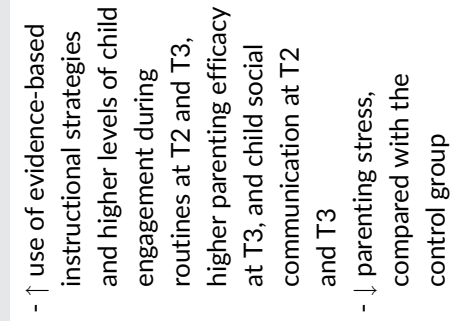

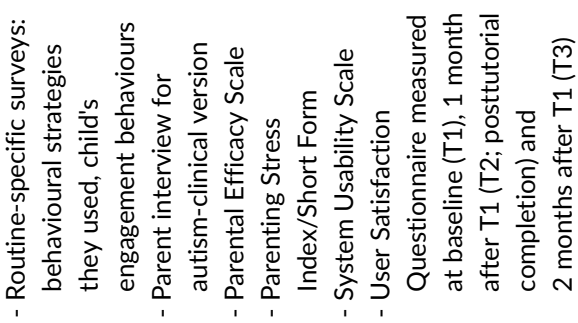

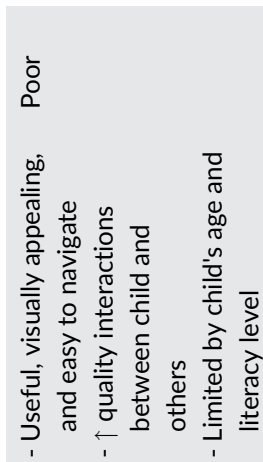

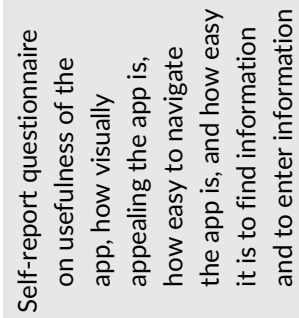

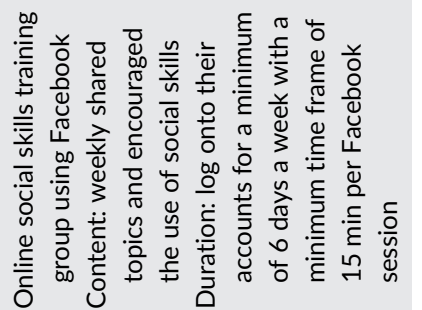

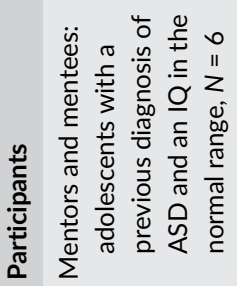

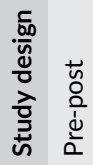

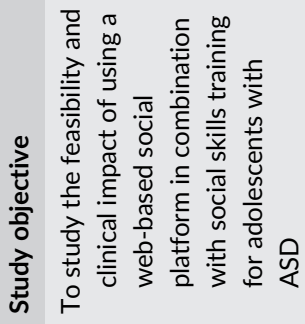

I

In

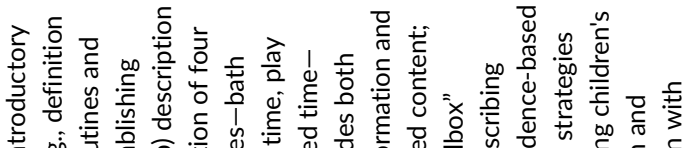

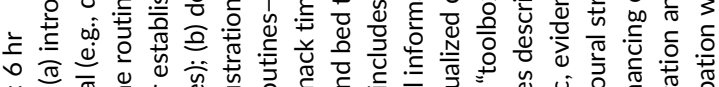

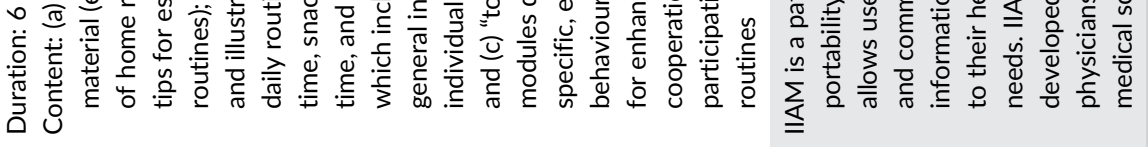

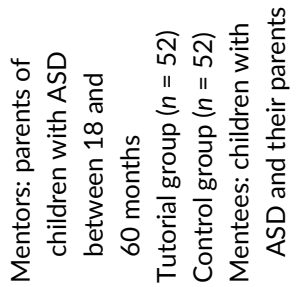

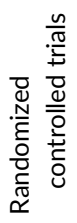

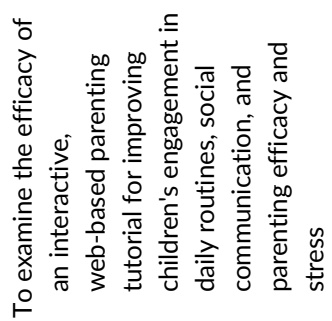

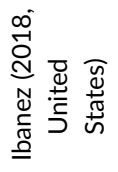

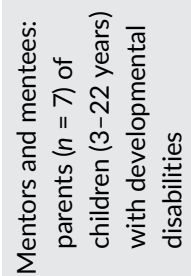

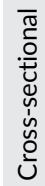

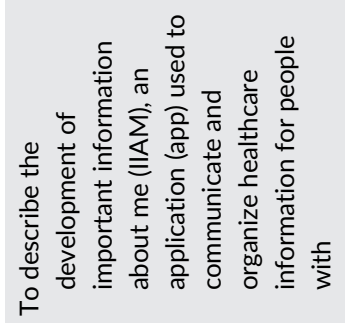

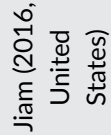




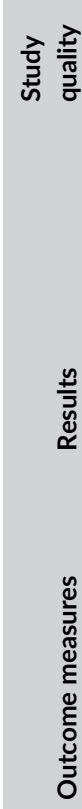

휸

เั

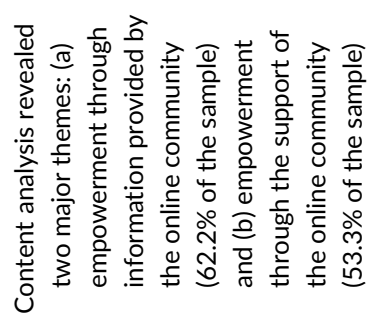

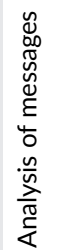
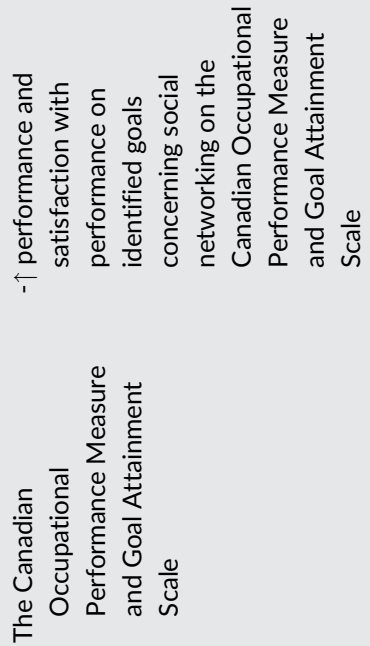

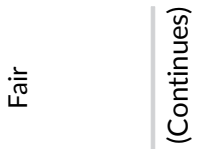
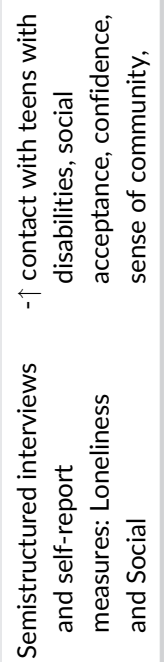

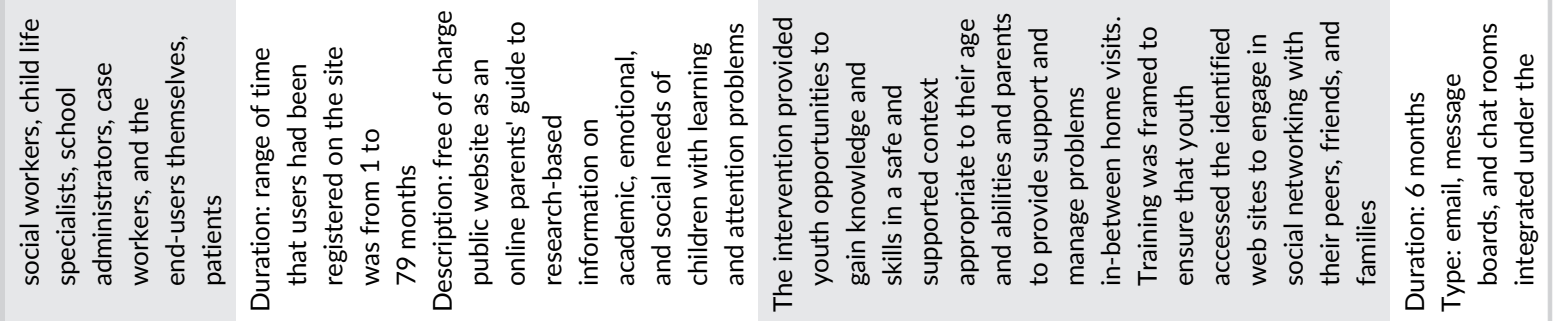
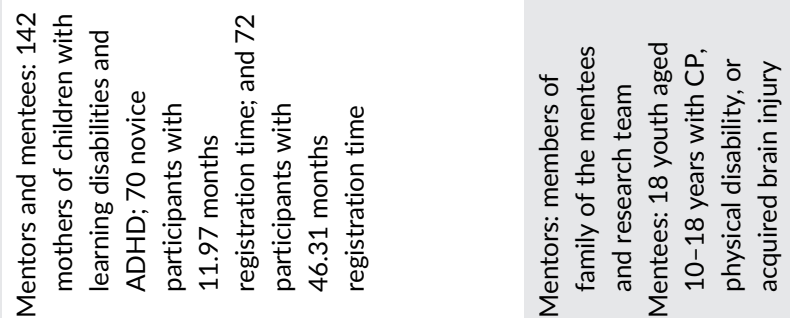

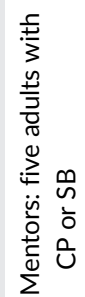

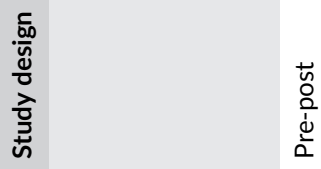

पूa
$\frac{0}{\dot{d}}$
$\dot{0}$

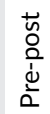
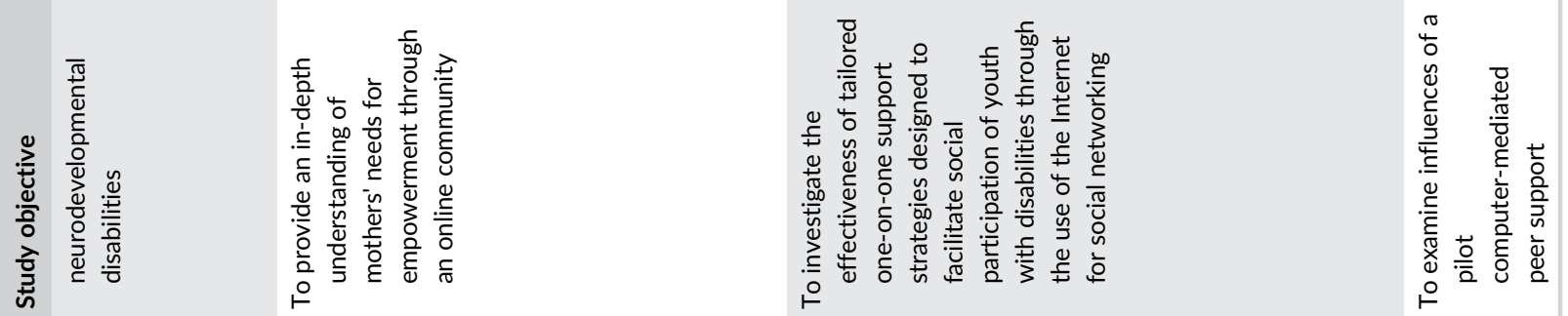

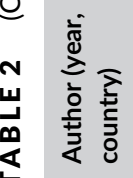

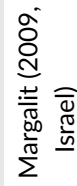
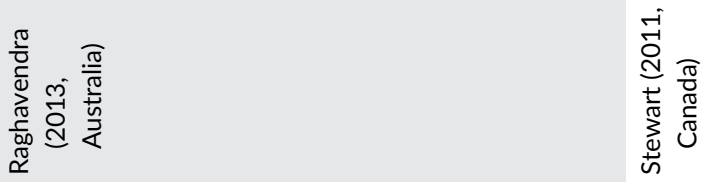


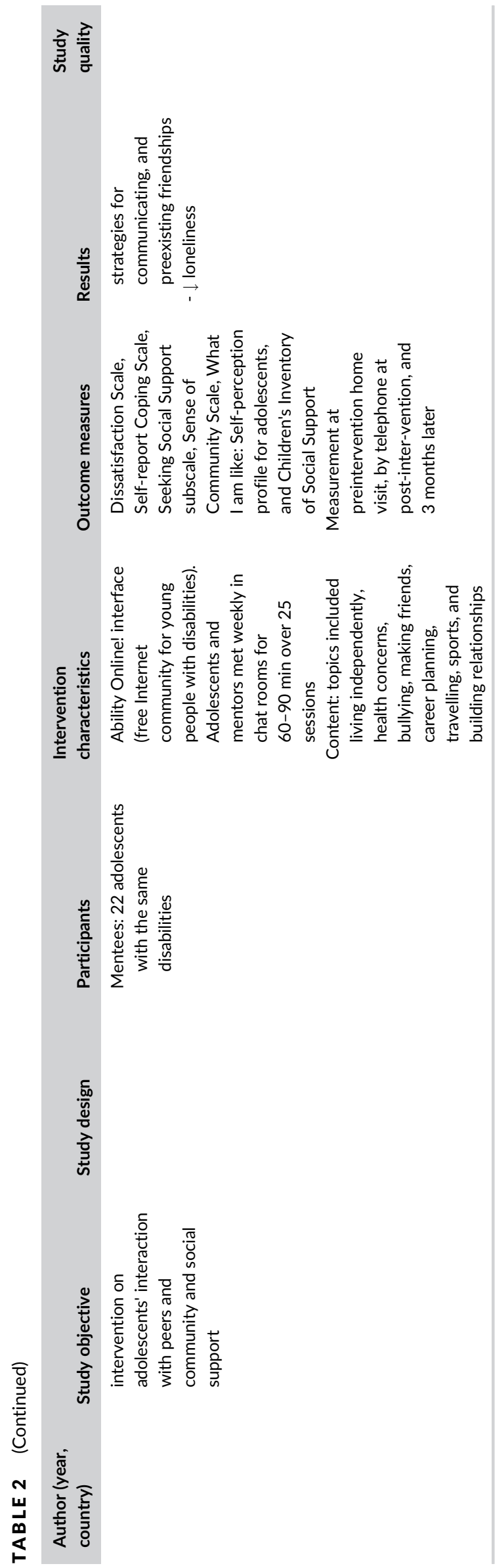

interrater agreement of $86.4 \%$ in $10 \%$ of the articles selected for data extraction before independently extracting the data from the remaining articles.

\section{5 | Data synthesis}

The quantitative studies included in this review used different questionnaires and self-report measures. As a result, we reported the data individually for each study. We analysed the qualitative studies using a thematic analysis approach, which allowed clear identification of themes arising from each study and enabled a certain level of abstraction. The first author (S. S.) conducted most of the synthesis, and findings were discussed regularly with the research team to ensure they reflected the original data appropriately. The thematic analysis and meta-synthesis processes, as outlined by Thomas and Harden (2008), were used to enhance transparency in the review process (Thomas \& Harden, 2008). Free line-by-line coding of the findings from the primary studies was done. Data were examined for meaning and content during the coding. The codes were then examined and analysed for their meanings and reorganized into related categories. Similar categories were merged into higher level constructs and then themes. These descriptive themes were then used to explore the research question and to draw on analytical themes that could describe the scope of the literature.

\section{6 | Quality and risk of bias assessment}

We used the Newcastle-Ottawa Scale for cross-sectional observational studies (Peterson, Welch, Losos, \& Tugwell, 2011) and the Cochrane Risk of Bias 2.0 Tool for randomized controlled trials (RCTs; Higgins \& Altman, 2008) in order to assess the quality of each study. The quality of the selected studies was assessed independently by two investigators (S. S. and J. M.).

\section{3 | RESULTS}

Figure 1 shows the Preferred Reporting Item for Systematic Review and Meta-analysis flow chart that demonstrates the selection of studies (Moher, Liberati, Tetzlaff, \& Altman, 2009). A total of 1,557 (PsycINFO-417, Medline-464, Embase-416, CINAHL-202, and Education Research Complete-58) articles were identified in the initial searching stage, and then 235 duplicate articles were removed. A total of 80 articles were selected for full-text review, and 11 articles met the inclusion criteria for this review. The majority of the studies took place in the United States $(n=5)$. Other studies were from Canada ( $n=3)$, Australia ( $n=1)$, Israel $(n=1)$, and South Africa $(n=1)$. The majority of studies reviewed used quasi-experimental/pre-post designs $(n=6)$. The others used quantitative methods, such as crosssectional surveys $(n=3)$, or qualitative methodology $(n=1)$ or were $\operatorname{RCT}(n=1)$. 


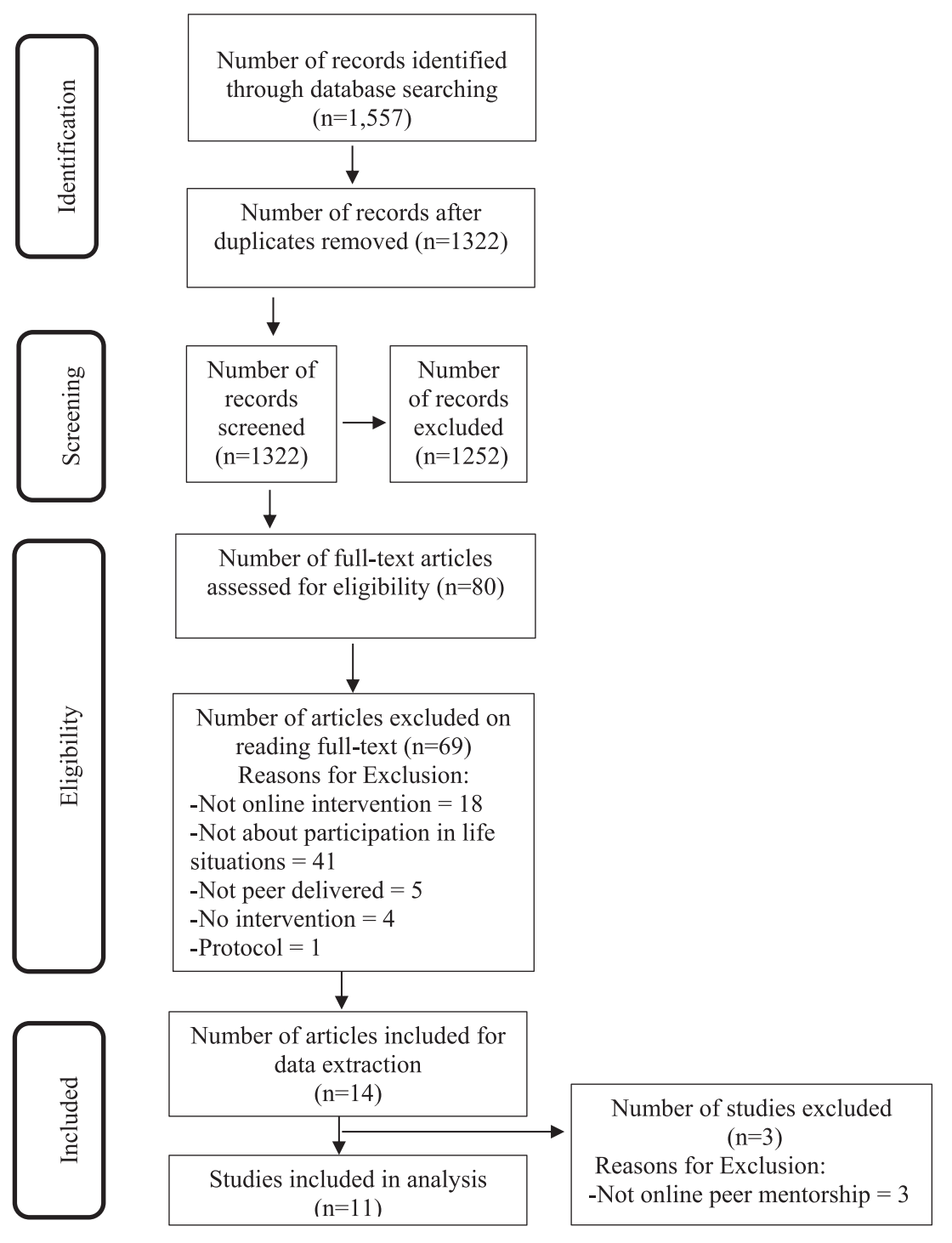

FIGURE 1 Preferred Reporting Item for Systematic Review and Meta-analysis flow diagram for the systematic review process

\subsection{Quality of studies and risk of bias assessment}

Few studies were considered of poor quality due to small sample size (Barnfather et al., 2011; Burgstahler \& Crawford, 2007; Cole et al., 2017; Gwynette et al., 2017; Jiam, Hoon Jr, Hostetter, \& Khare, 2017; Stewart et al., 2011), convenience sampling strategy (Burgstahler \& Crawford, 2007; Cross et al., 2018; Gwynette et al., 2017; Jiam, Hoon, Hostetter, \& Khare, 2017; Margalit \& Raskind, 2009; Stewart et al., 2011), and no description of validation of the assessment tool (Burgstahler \& Crawford, 2007; Cole et al., 2017). The risk of bias was assessed using the six domains of the Cochrane collaboration's tool for assessing risk of bias (Higgins \& Altman, 2008). Achieving participant and/or outcome assessor blinding was not explained for any study, resulting in an unclear risk of performance and detection bias. Six studies that used quasi-experimental/pre-post designs used nonrandom sampling techniques that raises some concerns regarding risk of selection bias (; ; Fenstermacher et al., 2006; ; ; Barnfather et al., 2011; Cross et al., 2018; Gwynette et al., 2017; Raghavendra et al., 2013; Stewart et al., 2011). The only RCT included in the review conducted intention-to-treat analyses, thus having a low risk of attrition bias (Ibañez et al., 2018). It had low risk of selection, performance, and detection bias as it used appropriate methods for sample selection, allocation to treatment groups, measuring outcomes, and reporting results (Ibañez et al., 2018).

\section{2 | Participants}

The disabilities included different diagnoses: cerebral palsy $(n=3$; Barnfather et al., 2011; Raghavendra et al., 2013; Stewart et al., 2011), autism spectrum disorder ( $n=3$; Cole et al., 2017; Gwynette et al., 2017; Ibañez et al., 2018), spina bifida ( $n=2$; Barnfather et al., 2011; Stewart et al., 2011), attention deficit hyperactivity disorder ( $n=2$; Fenstermacher et al., 2006), and other neurodevelopmental disorders. The mentors included in the studies were caregivers of children with disabilities (Cole et al., 2017; Cross et al., 2018; Ibañez et al., 2018; Jiam et al., 2017; Margalit \& Raskind, 2009; Raghavendra et al., 2013), adults with disabilities (Barnfather et al., 2011; Burgstahler \& 
Crawford, 2007; Stewart et al., 2011), youth with disabilities (Burgstahler \& Crawford, 2007; Gwynette et al., 2017), and a videotaped peer actor who was the same gender and approximate age as the youth with disabilities (Fenstermacher et al., 2006). The mentees included in the studies were youth with disabilities (age 10-19 years) and their families. The eligibility criteria for most study participants were an IQ above 80, access to the Internet, and Grades 4-6 reading level.

\section{3 | Characteristics of online peer mentorship programmes}

The online peer mentorship programmes found in this review had a variety of different characteristics. They included both structured and unstructured peer mentorship programmes. Structured peer mentorship programmes involved regular meetings and schedules (Fenstermacher et al., 2006; Gwynette et al., 2017; Raghavendra et al., 2013; Stewart et al., 2011). The mentors had the opportunity to consult with health professionals (psychologists and speech therapists) in cases of individual/challenging issues, and the topics of discussion were pre-decided. These health professionals acted like moderators, as they not only helped to develop discussions and maintain web-etiquette but also were a valuable resource to identify needs that could not be helped by the peer mentors like referring individuals to real life support as needed (Barnfather et al., 2011; Cole et al., 2017).

Participants led most conversations, but a moderator was present to give prompts on the topics if the conversation was stagnating. The main purpose of the moderators was to facilitate online discussions and to ensure that incorrect information, or sensitive topics such as personal information, were not divulged without permission. In the unstructured peer mentorship programmes, peer mentors and mentees were open to discuss whatever they liked (Cole et al., 2017; Margalit \& Raskind, 2009). Few studies had an online training module followed by chat sessions (Barnfather et al., 2011; Cross et al., 2018; Jiam et al., 2017). Regular meeting times were encouraged by all studies, but it appeared to be difficult to enforce regular meetings in chat rooms. The type of online supports included chat groups, "WhatsApp" (mobile App), "Facebook," electronic mail, message boards, and specific online interfaces. The group discussions included a broad range of topics that were directly and/or indirectly related to the life situations of youth with neurodevelopmental disabilities and included the following: independent living, making friends, bullying, career planning, travel, sports, building relationships, exchanging information with peers, social engagement, health concerns, long-term goals, therapy logs, communication methods, coping mechanisms, legal and financial assistance, feeding schedule, medication table, medical imaging findings, and self-perception of their own disability.

The content of some online programmes was determined by the needs and concerns shared by youth with disabilities and their family members as discussed in the scheduled chat sessions (Barnfather et al., 2011; Burgstahler \& Crawford, 2007; Jiam et al., 2017;
Margalit \& Raskind, 2009). Other more structured online interventions had predetermined content: "F-words in disability" (function, family, fitness, fun, friends, and future) tools and resources; the International Classification of Functioning, Disability and Health resources; fostering engagement, participation, and interest; and social problemsolving strategies (Cross et al., 2018; Fenstermacher et al., 2006; Ibañez et al., 2018). The sessions in the online programmes were 60-90 min and lasted anywhere between 8 and 24 weeks.

\subsection{Effect of online peer mentorship on patient- reported measures}

Only five studies (Fenstermacher et al., 2006; Gwynette et al., 2017; Ibañez et al., 2018; Raghavendra et al., 2013; Stewart et al., 2011) conducted quantitative analysis to demonstrate the effectiveness of online programmes/interactive tools/social groups on youth's ability to participate in life situations, using different measures. The number of participants in these studies with outcome measures varied from four to 142. As none of the studies used a common outcome measure, pooled analysis and effect size calculation could not be performed for this review. All five studies used a structured intervention programme where the content, frequency, and duration of the programme were fixed. All studies either provided individual supports to the participants or involved a facilitator to direct the discussion. Two of the five studies did not observe any significant effects of the intervention programmes on a quantitative social engagement measure, measured using a Social Skill Rating Scale (Gwynette et al., 2017; Stewart et al., 2011). Both studies attributed this to small sample sizes.

The other three studies showed significant improvements in youth engagement and social communication measured through either a social skills rating system (Cohen's $d=0.55-1.74$; Fenstermacher et al., 2006), Canadian Occupational Performance Measure ( $p$.001; Raghavendra et al., 2013), or child behaviour survey on child engagement (Cohen's $d=0.53-0.85$; Ibañez et al., 2018). One of the studies that involved parents identified a significant increase in the use of tips acquired from the mentor during their daily routines with their children (Cohen's $d=1.06-1.39$; Ibañez et al., 2018). These strategies incorporated a variety of evidence-based techniques, including providing simple verbal instructions, using visual schedules, and appropriately modifying routine steps. Only one of these studies was an RCT, also targeting parents or caregivers and where the control group and the tutorial group were comparable on child age, parental age, and parental education; and the intervention effects on child social communication lasted for 3 months postintervention (Ibañez et al., 2018). No other study controlled for any of these covariates. Three studies examined gender influences on the participation and outcomes and found females to have a significantly higher response rate/participation in online sessions (Barnfather et al., 2011; Cross et al., 2018; Stewart et al., 2011). It was also shown that males had smaller social networks, lower social acceptance and sense of community, more loneliness, and sought support less often (Stewart et al., 2011). 


\section{5 | Thematic analysis}

Studies used interviews/focus groups (Barnfather et al., 2011; Cole et al., 2017; Ibañez et al., 2018; Stewart et al., 2011), self-report questionnaires (Cross et al., 2018; Fenstermacher et al., 2006; Gwynette et al., 2017; Ibañez et al., 2018; Jiam et al., 2017; Raghavendra et al., 2013; Stewart et al., 2011), and direct observation or field notes (Barnfather et al., 2011; Fenstermacher et al., 2006) to understand the influences of online peer mentorship programmes on the participation in life situations among youth with disabilities. The results of these studies informed the following themes:

\subsection{1 | Types of support received}

Mentees mostly expressed receiving emotional and affirmation support to include listening to others, modelling confidence, offering friendship to those who felt alone, sharing their point of view on issues, providing practical advice, and sharing experiences related to disability. In fact, mentors believed they could provide affirmation support better than parents, friends, or doctors who did not have experiential knowledge (Barnfather et al., 2011). Other supports to mentees included communication and informational support (instructional advice, learning advice; Cole et al., 2017). Participants acknowledged the benefits of the intervention programmes on their ability to use Internet sites, disability-specific software, and social networking sites (Raghavendra et al., 2013).

\subsection{2 | Feasibility/utility}

The online support environment was identified as a safe space that fostered social exchange and social comparison (Barnfather et al., 2011; Cole et al., 2017). In addition, the virtual, nonvisible environment allowed the participants to openly express their opinions, which might not have been previously articulated because of their visible disability (Barnfather et al., 2011). Participants also reported that being a part of an online/WhatsApp support group saved travel costs (Cole et al., 2017). The ability to seek information and be readily support was a positive attribute of the WhatsApp support group (Cole et al., 2017). On the other hand, one common frustration for both participants and mentors/moderators was the technical challenge of using an unstable platform that periodically froze or logged people off the system (Barnfather et al., 2011). In addition, few other personal skills such as typing speed, reading comprehension, and an ability to follow rapid conversation also affected the utility of the intervention programmes (Barnfather et al., 2011). Few participants perceived the online interventions as being "enjoyable," "humorous," "interesting," "fun," and "cool" (Barnfather et al., 2011). Many participants found it hard to "speak" over chat room "noise" with multiple strings of text to read and limited opportunity for clarification and response (Barnfather et al., 2011). Despite prescreening for IQ in most of the studies, cognitive delays and decreased fine motor capacity affected some youth's capacity to manage the speed of online interaction and respond to questions (Barnfather et al., 2011).

\subsection{3 | Factors associated with the outcomes of peer mentorship intervention}

Based on the perceptions of participants and analysis by the research teams who delivered the intervention, there were some factors that were suggested to have an impact on the study outcomes. (a) Specificity of the programme-Programmes that used specific content and outcomes appeared to be more engaging for the participants. Unstructured interventions were perceived to be leading to negative discussions or a lack of contribution from some participants in the group (Cole et al., 2017). As a result, members of the group were not always able to speak about topics pertaining to everyday difficulties (Cole et al., 2017). Few participants shared that they would have preferred the participant groups to be more age-specific, allowing them to express more freely (Barnfather et al., 2011). (b) Availability of moderator/individual attentionModerators helped in facilitating the sessions and addressing challenging issues, which kept the discussions interesting and ensured participation of most participants (Barnfather et al., 2011; Cole et al., 2017; Fenstermacher et al., 2006; Gwynette et al., 2017; Raghavendra et al., 2013). (c) Heterogeneity among participantsAlthough some participants liked being exposed to many people of different cultures, races, and religious backgrounds, others felt that each individual is unique and encountered negative experiences with the discussion-"Group is sometimes overwhelmed or overshadowed by the socializing aspects that can therefore dampen the relevance of the group" (Cole et al., 2017).

\section{4 | DISCUSSION}

The purpose of this systematic review was to determine the impact of online peer support interventions for children with neurodevelopmental disabilities on their participation in life situations. One original RCT, six quasi-experimental studies, three cross-sectional surveys, and one qualitative study examined the influences of five different structured online peer mentorship intervention programmes (Barnfather et al., 2011; Fenstermacher et al., 2006; Ibañez et al., 2018; Raghavendra et al., 2013; Stewart et al., 2011) and six different online support groups (Burgstahler \& Crawford, 2007; Cole et al., 2017; Cross et al., 2018; Gwynette et al., 2017; Jiam et al., 2017; Stewart et al., 2011). Implementation of the online interventions varied across the studies but consistently showed a unique potential to facilitate social networking and support.

Findings revealed both similarities and differences in the key characteristics of online peer support interventions across all studies. No study in this review included children less than 10 years old, as most of the studies included children with a reading level of Grade 4 and above. Few studies catered to the specific challenges and needs 
of participants by involving a moderator who would work on an individual level with the participants. One study tailored the intervention to meet participants' personal goals by providing intensive and repeated one-to-one support and observed significant improvement in participants' performance and satisfaction (Raghavendra et al., 2013). Having a one-to-one support also allowed the recruitment of children with diverse disabilities.

In order to optimize engagement in interactive online programmes, a better understanding of participant-led values/goals for these interventions is required (Biddiss, Chan-Viquez, Cheung, \& King, 2019). For example, there may be multiple and differently valued goals for online peer mentorship interventions (interactionfocused, therapy/intervention-focused, and technology-focused). The latter might also be affected by the structure of the online interventions-individual attention, feedback, monitoring, and opportunities for social networking and interaction, and so on. These factors, if not integrated well in the development of intervention, might negatively impact affective, behavioural, and cognitive engagement in online programmes (Biddiss et al., 2019). However, the method by which key characteristics such as session duration, frequency, programme length, and programme format (moderator facilitated vs. free discussion) were chosen, or how these types of decisions were informed, was not discussed.

Absence of underlying theories or theoretical frameworks to support the online peer support interventions was notable, with only one study mentioning a theoretical framework that informed the study design (but was not a theory to inform intervention; Cross et al., 2018). As the interventions have multiple formats and are often specific to the type of disability, an integration of one or more empirical frameworks into online peer support interventions may aid in the development of more standardized intervention protocols and may target specific outcomes. Previous research suggests that self-determination theory, expectancy-value theory, or social cognitive theory could provide a suitable theoretical basis for online interventions involving children with neurodevelopmental disabilities (Biddiss et al., 2019).

This review found that online peer support interventions offered a variety of support-emotional, affirmational, and informational-that affected the participants' experiences during the intervention. The combination of supports resulted in social communication improvements (Barnfather et al., 2011; Cole et al., 2017; Fenstermacher et al., 2006; Ibañez et al., 2018; Raghavendra et al., 2013) and children's increased ability to engage during routines (Ibañez et al., 2018). This may suggest that improvements in routine-specific behaviours might be generalized to broader contexts and interactions in other life situations among children-self-care; communication; play; interpersonal interactions and relationships; community, social, and civic life; and learning and applying knowledge.

However, further research is required to corroborate these relationships. Among the other factors that might impact the success of an online peer intervention programme, the effect on gender needs to be further explored. In one of the studies that reported gender differences, females were significantly older than males (Stewart et al.,
2011). Therefore, the interaction effects of age and gender need to be further investigated.

There were very few negative outcomes reported in the online peer mentorship programmes. Some studies did take note of the disadvantages associated with the heterogeneity in disability groups that resulted in negative effects such as not being able to relate to the discussion, decreased participation, or deviation from the main issues (Barnfather et al., 2011; Cole et al., 2017). To avoid this, few mentors suggested to have an individual meeting with the participants before the online sessions to have a better idea of their expectations (Barnfather et al., 2011). Another disadvantage was the technical challenges and unstable online platforms that made it very difficult for both the mentors and participants to engage in uninterrupted discussions, further limiting the opportunities to respond and clarify content (Barnfather et al., 2011).

Further research is needed to fully assess the use of online peer mentorship programmes for youth with neurodevelopmental disabilities. Larger sample sizes are required to properly assess both quantitative and qualitative effects (Gwynette et al., 2017; Stewart et al., 2011). Additional research should focus on outcomes for both mentors and the mentees. The different roles that peers can play should also be investigated, as different peers may be able to provide different types of information and support (Burgstahler \& Crawford, 2007; Fenstermacher et al., 2006). This review indicated that online peer mentorship groups for youth with neurodevelopmental disabilities and their caregivers should consider similarities in participant profile. Similar individuals can relate to one another more easily, which facilitates relationship building. In future programmes, mentors could be paired with mentees based on similarities such as age, ability level, time of diagnosis, and geographic location. Finally, it is imperative to create a safe and informative space where participants feel comfortable having discussions online and where they can build relationships.

This review has limited generalizability, as only neurodevelopmental disabilities were examined, excluding mental disorders and other causes of physical disabilities such as arthritis. The reason for this limitation was the complexity needed in the search strategy to find these studies and the very large amount of evidence available. Another limitation of this study is that the study designs and formats of the online support groups were heterogeneous. Some studies included interactive online chat rooms, surveys of Internet experiences with peers, and even email chat forums. Although these formats both represent online peer mentorship, it is important to note that they are different and that this may reduce the credibility of the findings. The large date range used also limits the credibility of our results. We chose a large time range (1995 to present) to increase the scope of the study but acknowledge that the use of and exposure to Internet technologies has changed over time and that this element should be considered. We also acknowledge that this review only includes individuals who are able to access the Internet regularly enough to engage in online peer mentorship programmes.

The study designs were heterogeneous, and only one study was a randomized trial, which did not offer enough evidence to make conclusions on precise effectiveness of specific interventions. In the 
future, it will be important to consider the development of studies that can address the efficacy and test the best mechanisms for peer mentorship programmes in the future, in order to provide clear pathways to develop such programmes, including the most effective types of interventions, the dosage, the groups that can benefit the most, and the types of outcomes that can be expected. Interventions targeting youth with disabilities were also very limited in the studies retrieved, identifying a gap in the literature that should be addressed.

Potential source of bias in this review is the exclusion of grey literature. Existing online peer mentorship programmes that are not published were therefore excluded, and it is possible that publication bias resulted in studies with more positive outcomes being published. We tried to minimize bias by conducting a systematic search strategy developed by a librarian and a close consultation with a large group of coauthors in different fields of expertise. The data extracted are subject to interpretation, although these were accounted for by establishing strong interrater agreement before starting the data extraction and by maintaining an ongoing communication among the research team.

\section{5 | CONCLUSION}

Creating a large peer mentorship programme that has both face-toface and online components could be paramount for promoting the participation of children with disabilities in community activities such as leisure. The online component has great potential to promote participation due to higher accessibility, but the face-to-face component could foster more personal relationships. At the moment, clinicians may want to encourage youth and their caregivers to engage in online peer mentorship programmes if they are unable to easily access peer support in a face-to-face format, or if they are seeking for additional support systems. Further research is needed on online peer mentorship programmes for youth and caregivers of children with disabilities to establish specific parameters and standardized measures to evaluate the outcomes and protocols for better results steaming from this promising type of intervention.

\section{ORCID}

Shikha Saxena (D) https://orcid.org/0000-0001-7728-9234 Keiko Shikako-Thomas (D) https://orcid.org/0000-0002-4447-5812

\section{REFERENCES}

Anaby, D., Law, M., Coster, W., Bedell, G., Khetani, M., Avery, L., \& Teplicky, R. (2014). The mediating role of the environment in explaining participation of children and youth with and without disabilities across home, school, and community. Archives of Physical Medicine and Rehabilitation, 95(5), 908-917. https://doi.org/10.1016/j.apmr. 2014.01.005

Barnfather, A., Stewart, M., Magill-Evans, J., Ray, L., \& Letourneau, N. (2011). Computer-mediated support for adolescents with cerebral palsy or spina bifida. CIN: Computers, Informatics, Nursing, 29(1), 24-33.

Biddiss, E., Chan-Viquez, D., Cheung, S. T., \& King, G. (2019). Engaging Children with Cerebral Palsy in Interactive Computer Play-Based
Motor Therapies: Theoretical Perspectives. Disability and Rehabilitation, 18, 1-15. https://doi.org/10.1080/09638288.2019.1613681

Bozeman, B., \& Feeney, M. K. (2007). Toward a useful theory of mentoring a conceptual analysis and critique. Administration and Society, 39(6), 719-739.

Burgstahler, S., \& Crawford, L. (2007). Managing an e-mentoring community to support students with disabilities: A case study. AACE Journal, 15(2), 97-114.

Cole, L., Kharwa, Y., Khumalo, N., Reinke, J. S., \& Karrim, S. B. S. (2017) Caregivers of school-aged children with autism: Social media as a source of support. Journal of Child and Family Studies, 26(12), 3464-3475. https://doi.org/10.1007/s10826-017-0855-9

Coster, W., Law, M., Bedell, G., Khetani, M., Cousins, M., \& Teplicky, R. (2012). Development of the participation and environment measure for children and youth: Conceptual basis. Disability and Rehabilitation, 34(3), 238-246. https://doi.org/10.3109/09638288.2011. 603017

Coulson, N. S., Buchanan, H., \& Aubeeluck, A. (2007). Social support in cyberspace: A content analysis of communication within a Huntington's disease online support group. Patient Education and Counseling, 68(2), 173-178. https://doi.org/10.1016/j.pec.2007. 06.002

Cross, A., Rosenbaum, P., Grahovac, D., Brocklehurst, J., Kay, D., Baptiste, S., \& Gorter, J. W. (2018). A web-based knowledge translation resource for families and service providers (the "F-words" in Childhood Disability Knowledge Hub): Developmental and pilot evaluation study. JMIR Rehabilitation and Assistive Technologies, 5(2), e10439-e10439. https://doi.org/10.2196/10439

Dahan-Oliel, N., Shikako-Thomas, K., \& Majnemer, A. (2012). Quality of life and leisure participation in children with neurodevelopmental disabilities: A thematic analysis of the literature. Quality of Life Research, 21 (3), 427-439. https://doi.org/10.1007/s11136-011-0063-9

Fenstermacher, K., Olympia, D., \& Sheridan, S. M. (2006). Effectiveness of a computer-facilitated interactive social skills training program for boys with attention deficit hyperactivity disorder. School Psychology Quarterly, 21(2), 197-224.

Gwynette, M. F., Morriss, D., Warren, N., Truelove, J., Warthen, J., Ross, C. P., ... Borckardt, J. (2017). Social skills training for adolescents with autism spectrum disorder using facebook (project rex connect): A survey study. JMIR Mental Health, 4(1), e4. https://doi.org/10.2196/ mental.6605

Higgins, J. P., \& Altman, D. G. (2008). Assessing risk of bias in included studies. Cochrane handbook for systematic reviews of interventions: Cochrane book series, 187-241.

Ibañez, L. V., Kobak, K., Swanson, A., Wallace, L., Warren, Z., \& Stone, W. L. (2018). Enhancing interactions during daily routines: A randomized controlled trial of a web-based tutorial for parents of young children with ASD. Autism Research, 11(4), 667-678. https:// doi.org/10.1002/aur.1919

Jiam, N., Hoon, A. Jr., Hostetter, C., \& Khare, M. (2017). IIAM (important information about me): A patient portability profile app for adults, children and families with neurodevelopmental disabilities. Disability and Rehabilitation. Assistive Technology, 12(6), 599-604. https://doi.org/ 10.1080/17483107.2016.1198435

Lasker, J. N., Sogolow, E. D., \& Sharim, R. R. (2005). The role of an online community for people with a rare disease: Content analysis of messages posted on a primary biliary cirrhosis mailinglist. Journal of Medical Internet Research, 7(1), e10. https://doi.org/10.2196/jmir.7.1.e10

Margalit, M., \& Raskind, M. H. (2009). Mothers of children with LD and ADHD: Empowerment through online communication. Journal of Special Education Technology, 24(1), 39-49.

Moher, D., Liberati, A., Tetzlaff, J., \& Altman, D. G. (2009). Preferred reporting items for systematic reviews and meta-analyses: The PRISMA statement. Annals of Internal Medicine, 151(4), 264-269. https:// doi.org/10.7326/0003-4819-151-4-200908180-00135 
Organization, W. H. (2002). Towards a common language for functioning, disability, and health: ICF. The International Classification of Functioning, DisaB11bility and Health.

Peterson, J., Welch, V., Losos, M., \& Tugwell, P. (2011). The NewcastleOttawa scale (NOS) for assessing the quality of nonrandomised studies in meta-analyses. Ottawa: Ottawa Hospital Research Institute.

Raghavendra, P., Newman, L., Grace, E., \& Wood, D. (2013). 'I could never do that before': Effectiveness of a tailored Internet support intervention to increase the social participation of youth with disabilities. Child: Care, Health and Development, 39(4), 552-561.

Shikako-Thomas, K., Shevell, M., Schmitz, N., Lach, L., Law, M., Poulin, C., ... Group, Q. (2013). Determinants of participation in leisure activities among adolescents with cerebral palsy. Research in Developmental Disabilities, 34(9), 2621-2634. https://doi.org/10.1016/j.ridd.2013. 05.013

Stewart, M., Barnfather, A., Magill-Evans, J., Ray, L., \& Letourneau, N. (2011). Brief report: An online support intervention: Perceptions of adolescents with physical disabilities. Journal of Adolescence, 34(4), 795-800. https://doi.org/10.1016/j.adolescence.2010.04.007

Thomas, J., \& Harden, A. (2008). Methods for the thematic synthesis of qualitative research in systematic reviews. BMC Medical Research Methodology, 8(1), 1-10.

How to cite this article: Saxena S, Mitchell J, Ehsan A, Majnemer A, Shikako-Thomas K. Online peer mentorship programmes for children and adolescents with neurodevelopmental disabilities: A systematic review. Child Care Health Dev. 2020;46:132-148. https://doi.org/10.1111/ cch.12726 
APPENDIX A.: | PRISMA 2019 CHECKLIST

\begin{tabular}{|c|c|c|c|}
\hline Section/topic & $\#$ & Checklist item & Reported on page \# \\
\hline \multicolumn{4}{|l|}{ TITLE } \\
\hline Title & 1 & $\begin{array}{l}\text { Identify the report as a systematic review, } \\
\text { meta-analysis, or both. }\end{array}$ & 1 \\
\hline \multicolumn{4}{|l|}{ ABSTRACT } \\
\hline Structured summary & 2 & $\begin{array}{l}\text { Provide a structured summary including, as applicable: } \\
\text { background; objectives; data sources; study } \\
\text { eligibility criteria, participants, and interventions; } \\
\text { study appraisal and synthesis methods; results; } \\
\text { limitations; conclusions and implications of key } \\
\text { findings; systematic review registration number. }\end{array}$ & 2 \\
\hline \multicolumn{4}{|l|}{ INTRODUCTION } \\
\hline Rationale & 3 & $\begin{array}{l}\text { Describe the rationale for the review in the context of } \\
\text { what is already known. }\end{array}$ & 3 \\
\hline \multicolumn{4}{|l|}{ METHODS } \\
\hline Protocol and registration & 5 & $\begin{array}{l}\text { Indicate if a review protocol exists, if and where it can } \\
\text { be accessed (e.g., Web address), and, if available, } \\
\text { provide registration information including } \\
\text { registration number. }\end{array}$ & 4 \\
\hline Eligibility criteria & 6 & $\begin{array}{l}\text { Specify study characteristics (e.g., PICOS, length of } \\
\text { follow-up) and report characteristics (e.g., years } \\
\text { considered, language, publication status) used as } \\
\text { criteria for eligibility, giving rationale. }\end{array}$ & 4 \\
\hline Study selection & 9 & $\begin{array}{l}\text { State the process for selecting studies (i.e., screening, } \\
\text { eligibility, included in systematic review, and, if } \\
\text { applicable, included in the meta-analysis). }\end{array}$ & 4 \\
\hline Data collection process & 10 & $\begin{array}{l}\text { Describe method of data extraction from reports } \\
\text { (e.g., piloted forms, independently, in duplicate) and } \\
\text { any processes for obtaining and confirming data } \\
\text { from investigators. }\end{array}$ & 4 \\
\hline Data items & 11 & $\begin{array}{l}\text { List and define all variables for which data were sought } \\
\text { (e.g., PICOS, funding sources) and any assumptions } \\
\text { and simplifications made. }\end{array}$ & 4 \\
\hline Risk of bias in individual studies & 12 & $\begin{array}{l}\text { Describe methods used for assessing risk of bias of } \\
\text { individual studies (including specification of whether } \\
\text { this was done at the study or outcome level), and } \\
\text { how this information is to be used in any data } \\
\text { synthesis. }\end{array}$ & 5 \\
\hline Summary measures & 13 & $\begin{array}{l}\text { State the principal summary measures (e.g., risk ratio, } \\
\text { difference in means). }\end{array}$ & 4 \\
\hline Synthesis of results & 14 & $\begin{array}{l}\text { Describe the methods of handling data and combining } \\
\text { results of studies, if done, including measures of } \\
\text { consistency }\left(\text { e.g., }\left.\right|^{2}\right) \text { for each meta-analysis. }\end{array}$ & 4 \\
\hline
\end{tabular}




\begin{tabular}{|c|c|c|c|}
\hline Section/topic & \# & Checklist item & $\begin{array}{l}\text { Reported on } \\
\text { page \# }\end{array}$ \\
\hline $\begin{array}{l}\text { Risk of bias } \\
\text { across studies }\end{array}$ & 15 & $\begin{array}{l}\text { Specify any assessment of risk of bias that may affect the cumulative evidence (e.g., publication bias, } \\
\text { selective reporting within studies). }\end{array}$ & 5 \\
\hline $\begin{array}{l}\text { Additional } \\
\text { analyses }\end{array}$ & 16 & $\begin{array}{l}\text { Describe methods of additional analyses (e.g., sensitivity or subgroup analyses, meta-regression), if done, } \\
\text { indicating which were pre-specified. }\end{array}$ & $\begin{array}{l}\text { Not } \\
\text { applicable }\end{array}$ \\
\hline \multicolumn{4}{|l|}{ RESULTS } \\
\hline Study selection & 17 & $\begin{array}{l}\text { Give numbers of studies screened, assessed for eligibility, and included in the review, with reasons for } \\
\text { exclusions at each stage, ideally with a flow diagram. }\end{array}$ & 5 \\
\hline $\begin{array}{l}\text { Study } \\
\text { characteristics }\end{array}$ & 18 & $\begin{array}{l}\text { For each study, present characteristics for which data were extracted (e.g., study size, PICOS, follow-up } \\
\text { period) and provide the citations. }\end{array}$ & 5 \\
\hline $\begin{array}{l}\text { Risk of bias } \\
\text { within studies }\end{array}$ & 19 & Present data on risk of bias of each study and, if available, any outcome level assessment (see item 12). & 5 \\
\hline $\begin{array}{l}\text { Results of } \\
\text { individual } \\
\text { studies }\end{array}$ & 20 & $\begin{array}{l}\text { For all outcomes considered (benefits or harms), present, for each study: (a) simple summary data for } \\
\text { each intervention group (b) effect estimates and confidence intervals, ideally with a forest plot. }\end{array}$ & 6 \\
\hline $\begin{array}{l}\text { Synthesis of } \\
\text { results }\end{array}$ & 21 & Present results of each meta-analysis done, including confidence intervals and measures of consistency. & $\begin{array}{l}\text { Not } \\
\text { applicable }\end{array}$ \\
\hline $\begin{array}{l}\text { Risk of bias } \\
\text { across studies }\end{array}$ & 22 & Present results of any assessment of risk of bias across studies (see Item 15). & 5 \\
\hline $\begin{array}{l}\text { Additional } \\
\text { analysis }\end{array}$ & 23 & $\begin{array}{l}\text { Give results of additional analyses, if done (e.g., sensitivity or subgroup analyses, meta-regression [see } \\
\text { Item 16]). }\end{array}$ & $\begin{array}{l}\text { Not } \\
\text { applicable }\end{array}$ \\
\hline \multicolumn{4}{|l|}{ DISCUSSION } \\
\hline $\begin{array}{c}\text { Summary of } \\
\text { evidence }\end{array}$ & 24 & $\begin{array}{l}\text { Summarize the main findings including the strength of evidence for each main outcome; consider their } \\
\text { relevance to key groups (e.g., healthcare providers, users, and policy makers). }\end{array}$ & 9 \\
\hline Limitations & 25 & $\begin{array}{l}\text { Discuss limitations at study and outcome level (e.g., risk of bias), and at review-level (e.g., incomplete } \\
\text { retrieval of identified research, reporting bias). }\end{array}$ & 10 \\
\hline Conclusions & 26 & $\begin{array}{l}\text { Provide a general interpretation of the results in the context of other evidence, and implications for } \\
\text { future research. }\end{array}$ & 11 \\
\hline \multicolumn{4}{|l|}{ FUNDING } \\
\hline Funding & 27 & $\begin{array}{l}\text { Describe sources of funding for the systematic review and other support (e.g., supply of data); role of } \\
\text { funders for the systematic review. }\end{array}$ & $\begin{array}{l}\text { Not } \\
\text { applicable }\end{array}$ \\
\hline
\end{tabular}

From: Moher D, Liberati A, Tetzlaff J, Altman DG, The PRISMA Group (2009). Preferred Reporting Items for Systematic Reviews and Meta-Analyses: The PRISMA Statement. PLoS Med 6(7): e1000097. doi:10.1371/journal.pmed1000097. For more information, visit: www.prisma-statement.org.

\section{APPENDIX B.: | SEARCH STRATEGY}

1. internet/

2. blogging/

3. social media/

4. e-mail/

5. mobile phone/or smartphone/

6. text messaging/

7. (online or internet or computer-mediated or social media or virtual or web or email* or e-mail* or blogging or on-line or live chat or facebook or myspace or twitter or cyberspace or instant messaging or chat room* or discussion forum* or texting or text messag* or apps or app or ((mobile or smart*) adj3 (technolog* or device? or phone? or application*))).ti,ab,kw.

8. 1 or 2 or 3 or 4 or 5 or 6 or 7

9. handicapped child/

10. developmental disorder/or developmental delay/

11. psychomotor disorder/ or developmental coordination disorder/or exp hyperactivity/or psychomotor retardation/

12. Down syndrome/

13. autism/

14. attention deficit disorder/

15. Asperger syndrome/

16. communication disorder/

17. intellectual impairment/

18. psychomotor disorder/

19. motor dysfunction/or immobility/or limited mobility/

20. tic/

21. Gilles de la Tourette syndrome/

22. cerebral palsy/

23. exp muscular dystrophy/ 
24. exp spinal dysraphism/

25. (disabilit* or disabled).ti,ab,kw.

26. (development* adj3 (disorder* or handicap*)).ti,ab,kw.

27. (neuro* adj2 (disorder* or condition* or disease*)).ti,ab,kw.

28. (attention deficit adj3 disorder*).ti,ab,kw.

29. (autism* or autistic* or asperger*).ti,ab,kw.

30. ((motor skills or movement) adj2 disorder*).ti,ab,kw.

31. (tic disorder* or tourette syndrome).ti,ab,kw.

32. (spina bifida or muscular dystroph* or down syndrome or cerebral palsy).ti,ab,kw.

33. 9 or 10 or 11 or 12 or 13 or 14 or 15 or 16 or 17 or 18 or 19 or 20 or 21 or 22 or 23 or 24 or 25 or 26 or 27 or 28 or 29 or 30 or 31 or 32

34. friend/

35. exp peer group/

36. mentor/

37. friendship/

38. social support/
39. cooperation/

40. self help/

41. (peer* or friend*).ti,ab,kw.

42. (mentor* or coach*).ti,ab,kw.

43. (((social or peer?) adj2 (support* or network*)) or ((support or self-help) adj2 group*)).ti,ab,kw.

44. ((peer? adj2 peer?) or (psycho* adj2 support*)).ti,ab,kw.

45. 34 or 35 or 36 or 37 or 38 or 39 or 40 or 41 or 42 or 43 or 44

46. child/

47. exp child/or exp adolescent/

48. (pediatric* or child* or adolescen* or teen* or juvenile*).ti,ab,kw.

49. 47 or 48

50. 8 and 33 and 45 and 49

51. (abstract report or books or "book review" or chapter or conference abstract or conference paper or "conference review" or editorial or erratum or letter or note or patent or reports or "review").pt.

52. 50 not 51 